\title{
Progress towards clover cyst nematode resistant white clover
}

\author{
J. VAN DEN BOSCH and C.F. MERCER \\ AgResearch Grasslands, Private Bag 11008, Palmerston North
}

\begin{abstract}
Clover cyst nematode (Heterodera trifolii) reduces growth and nutrient uptake of white clover (Trifolium repens) in New Zealand, and breeding resistant cultivars is the preferred control method for ecological and economic reasons. Resistant and susceptible selections were taken from a wide range of white clover seedlines. Selected plants were intercrossed and reselected over two cycles of selection. Cysts per gram of root dry weight (cysts/ g) was the measure of resistance used, with low cysts/g plants being more resistant. The mean cysts/ $\mathrm{g}$ value of the progenies from resistant parents was $69 \%$ of the mean value of the progenies from susceptible parents in the first generation, and $38 \%$ in the second generation. Root weights were similar, while the resistant selections had 58\% and $34 \%$ (first and second generations respectively) of the number of cysts in the susceptible selections. There were no immune plants ( 0 cysts) in the first generation and only two in the second. Counts were made of cysts, eggs per cyst and eggs per plant on clones of two resistant and two susceptible genotypes. The resistant genotypes had lower counts than the susceptible genotypes in terms of cysts per plant (means of $6 \mathrm{cf}$. 108), eggs per cyst (11 cf. 21) and eggs per plant (35 cf. 1650). The differences in numbers of cysts between resistant and susceptible lines increased during two generations of selection, supporting earlier results that indicated that progress in breeding for resistance was possible. Furthermore, the resistance is also acting on clover cyst nematode egg production which would further reduce recruitment to later generations of clover cyst nematode.
\end{abstract}

Keywords: breeding, Heterodera trifolii, resistance, screening, selection, Trifolium repens

\section{Introduction}

The clover cyst nematode (Heterodera trifolii Goffart) occurs throughout New Zealand (Mercer \& Woodfield 1986) and causes a general root malfunction and an accompanying depression of foliage growth in white clover (Trifolium repens L.). Reductions in growth, nitrogen content and efficiency of phosphorus utilisation have been measured in pot experiments of nematode infected white clover (Skipp \& Gaynor 1987; Widdowson et al. 1973; Yeates 1977). Field trials in the USA measured dry weight reductions of $14 \%$ and $46 \%$ for two lines of white clover (Norton 1967). In New Zealand, pesticide treatment that reduced a number of nematode species including clover cyst nematode, was associated with increases in pasture yield (mean of $13 \%$ ), clover yield (mean of $40 \%$ ) and nitrogen fixation (mean of 57\%) over 16 North Island sites (Watson et al. 1985). Greater responses were found on Bay of Plenty soils and a Hamilton site where nematode control gave better clover persistence during a summer drought resulting in a greater advantage in clover growth and $\mathrm{N}$ fixation in the following autumn and winter especially (Watson et al. 1994).

Nematicides for nematode control are not viable for economic and ecological reasons, and breeding resistant white clover cultivars is the most desirable alternative. Even partial resistance would be of benefit as an additional pressure on pest nematode populations. Resistant plants are ones on which nematode reproduction is prevented or reduced relative to susceptible controls. Some variation in resistance (relative or partial resistance), but no immunity (complete resistance) to the clover cyst nematode has been reported in white clover. Dijkstra (1971) used a range of material including apparently resistant New Zealand white clover and concluded that inheritance was most likely determined by more than one gene. However, Yeates et al. (1973) tested seven lines, including Grasslands Huia, and found all were susceptible. An increase in resistance in lines selected for seedling vigour in field soil was reported by Mercer et al. (1992).

The aim of the experiments reported here was to identify variation in resistance to clover cyst nematode in progenies from resistant white clover plants. Resistant and susceptible selections were taken from a wide range of white clover seedlines tested previously. Pair crosses were made within these resistant and susceptible selection groups to provide the first generation progeny (tested in Experiment 1 \& van den Bosch et al. 1993a) ; the second generation was produced from five 
polycrosses (three resistant and two susceptible, tested in Experiment 2). Previous results from this breeding programme have been published ( van den Bosch et al. 1993a; van den Bosch et al. 1997).

\section{Materials and methods}

To test for resistance, 10 pre-germinated white clover genotypes per seedline were sown at one seedling per pot, in $6 \mathrm{~cm}$ diameter pots containing a pasteurised sand-soil mix (Manawatu silt loam, $\mathrm{pH}$ 6.1). The pots were placed in randomised blocks, in metal trays, which were rotated weekly within the glasshouse. Pots were kept in temperature-controlled glasshouses with soil temperature at $18-24^{\circ} \mathrm{C}$, and total nutrients were applied fortnightly. Each pot was inoculated with approximately 2000 clover cyst nematode eggs in a $3 \mathrm{ml}$ suspension placed in a hole near the roots and the hole filled in. The nematodes used were from a culture initiated from fieldcollected cysts at Palmerston North and maintained on white clover. At harvest, roots were washed in elutriation towers (Wood \& Foot 1977) in which cysts and soil organic matter were washed up free of mineral particles that sank in the water flow. The cysts and organic matter were collected in fine sieves, and cysts counted. Roots were dried and weighed, and stolon tips kept to maintain all the plants for possible further selection and crossing. All selections were based on individual genotype data, not the seedline means.

Four "benchmark" seedlines sown in both Experiments 1 and 2 allow comparisons between experiments. The benchmark lines were a Grasslands Huia parent progeny, Ladino Gigante Lodigiano, Espanso, and a Heterodera-resistant seedline from SVP, Netherlands. Cysts per gram of root dry weight (referred to from here as cysts/g) was calculated by dividing the number of cysts by the root dry weight for each genotype. Means were compared by ANOVA, using GENSTAT.

\section{Experiment 1: First generation progeny evaluation}

The seedlines screened were 56 resistant and 12 susceptible first generation progeny sown in April 1990. Total nutrients were applied fortnightly: $\mathrm{N} 111$ (as $\mathrm{NH}_{4}^{+}$), P 40, K 238, S 60, Ca 127, Na 88, Cl 723, Mg 21, Fe 3, B 0.1, Zn 0.25, Mn 0.25, Cu 0.05, Mo 0.01 and Co $0.009 \mathrm{ppm}$. Plants were inoculated $3 \frac{1}{2}$ weeks after sowing, and harvested 6 weeks after inoculation. A shoot growth score $(1=$ smallest to $5=$ largest $)$ was visually assessed just before harvest time, to record plant performance, check experimental procedures and allow comparisons between shoot and root growth.
Experiment 2: Second generation progeny evaluation The seedlines screened were 91 resistant and 18 susceptible second generation progeny sown in January 1992. 'Thrive' nutrient solution was applied at halfstrength every 2 weeks. Plants were trimmed and repotted in March, inoculated after 2 weeks and then again 1 week later, and harvested 7 weeks after the first inoculation.

\section{Experiment 3: Eggs per cyst experiment}

Cuttings of two resistant and two susceptible genotypes from first generation progeny (van den Bosch et al. 1993a) were rooted for study of nematode egg production in June 1990. Five to nine copies (stolon tips) of each genotype were trimmed to standardise the leaf number and root mass, and inoculated as described above, a week later. Plants were maintained as before and 7 weeks after inoculation, cysts were extracted as described above and counted. Up to 10 cysts per plant were selected at random and crushed between a microscope slide and coverslip, and eggs counted. "Eggs per plant" values were the product of cysts per plant and the mean of the eggs per cyst values.

\section{Results}

There were highly significant differences (ANOVA Ftest $\mathrm{P}<0.001$ ) between individual seedlines in both generations for number of cysts, root dry weight, growth score (only scored in Experiment 1) and cysts/g. When individual seedlines were grouped on their selection criteria, the mean cysts/g value of the progenies from resistant parents was $69 \%$ of the mean value of the progenies from susceptible parents in the first generation (Table 1), and $38 \%$ in the second generation (Table 2). Root weights were similar for the three groups. The resistant selections had 58\% and 34\% (Experiments 1 and 2 respectively) of the number of cysts on the susceptible selections (Tables 1 and 2). There were no immune plants ( 0 cysts $)$ in the first generation; however, two were identified in the second. The benchmark lines had fewer cysts and cysts/g than the susceptible selections and were not significantly different from the resistant selections in Experiment 1, but were intermediate between resistant and susceptible selections for cysts in Experiment 2.

The number of cysts (and females) on cuttings of two resistant and two susceptible genotypes reflected the genotypes' status in the screening. The trend in eggs per cyst was not significant at $5 \%$, but there were significantly fewer eggs per plant on resistant genotypes (Table 3); the two resistant genotypes had a mean of 35 
eggs/plant, compared with 1650 for the two susceptible genotypes.

\section{Discussion}

These experiments confirm predictions (van den Bosch et al. 1997) based on the variability and broad sense heritabilities of the parent material that progress in breeding for resistance was possible. The divergence, in terms of cysts/g, in these early cycles of selection is encouraging progress for the breeding programme. Similar results have been found in a parallel programme breeding for resistance to the root-knot nematode, Meloidogyne sp. (van den Bosch \& Mercer 1996a, 1996b; van den Bosch et al. 1993b), though the rate of progress was slower.

Kuiper (1960) tested clones selected from nematodeinfested fields, and found several were "virtually resistant", though none were "absolutely resistant". These clones were from a range of cultivars from many countries, with the resistant clones coming from six different countries (Kuiper 1960). The parent plants of the selections described in this paper also came from a wide range of overseas and New Zealand germplasm.

Genetic variation among New Zealand's clover cyst nematode populations may limit the usefulness of this resistance selected against one population. However, the survey of North Island populations by Mercer \& Grant (1993) showed that six out of eight populations tested were sensitive to the resistant seedlines, and there was a seedline $\mathrm{x}$ nematode population interaction. Although a preliminary result, because of the moderate level of resistance in the plants used, their result indicated that the resistance being developed against a Palmerston North population of clover cyst nematode will probably have widespread applicability.

Differences in ability to host clover cyst nematode between genotypes are greater when the parasite population is measured as eggs/plant rather than the easier to measure cysts/plant. However, selecting for cysts/plant was effective in terms of both eggs/plant and cysts/plant after just one generation. Partial resistance, as seen in this white clover, can improve plant growth directly by reducing the debilitation owing to nematode feeding and also indirectly by lowering the number of nematodes in subsequent generations, thereby diminishing the soil population density of potential parasites. Our
Table 2 Mean number of Heterodera trifolii cysts, root dry weight, and cysts/g on three groups of $T$. repens second generation progeny seedlines in Experiment 2 (10 genotypes/seedline).

\begin{tabular}{|c|c|c|c|c|c|}
\hline \multirow[t]{2}{*}{ Selection } & \multirow{2}{*}{$\begin{array}{l}\text { Lines } \\
\text { (no.) }\end{array}$} & \multirow{2}{*}{$\begin{array}{l}\text { Cysts } \\
\text { (no.) }\end{array}$} & \multirow{2}{*}{$\begin{array}{l}\text { Root } \\
\text { dry weight } \\
\text { (g) }\end{array}$} & \multicolumn{2}{|c|}{ Cysts/g root DWt } \\
\hline & & & & Mean & Range \\
\hline Resistant & 91 & $82 \mathrm{C}$ & 0.283 & $341 \mathrm{~B}$ & $104-879$ \\
\hline Susceptible & 18 & $242 \mathrm{~A}$ & 0.304 & $895 \mathrm{~A}$ & $551-1190$ \\
\hline Benchmark & 4 & $122 \mathrm{~B}$ & 0.342 & $405 \mathrm{~B}$ & $198-625$ \\
\hline $\begin{array}{l}\text { Significance } \\
\text { (Selections) }\end{array}$ & & $* * *$ & n.s. & $* * *$ & \\
\hline $\begin{array}{l}\text { Significance } \\
\text { (Lines) }\end{array}$ & & $* * *$ & $* * *$ & $* * *$ & \\
\hline $\mathrm{LSD}_{0.05}$ & & & & & 277 \\
\hline
\end{tabular}

Means in a column with the same letter are not significantly different.

Table 3 Effect on egg numbers in Heterodera trifolii cysts after one cycle of selection for reduced cyst numbers on white clover in Experiment 3.

\begin{tabular}{lcccr}
\hline Genotype & $\begin{array}{c}\text { Number of } \\
\text { copies }\end{array}$ & $\begin{array}{c}\text { Mean females }+ \\
\text { cysts/plant }\end{array}$ & $\begin{array}{c}\text { Mean } \\
\text { eggs/cyst }\end{array}$ & $\begin{array}{c}\text { Mean } \\
\text { eggs/plant }\end{array}$ \\
\hline 84/12 (resistant) & 6 & $8 \mathrm{~A}$ & 16 & $61 \mathrm{~A}$ \\
88/15 (resistant) & 5 & $4 \mathrm{~A}$ & 6 & $9 \mathrm{~A}$ \\
90/7 (susceptible) & 9 & $100 \mathrm{~B}$ & 21 & $1560 \mathrm{~B}$ \\
82/15 (susceptible) & 9 & $115 \mathrm{~B}$ & 21 & $1740 \mathrm{~B}$ \\
Significance & & ${ }^{* * *}$ & n.s. & $* *$ \\
\hline
\end{tabular}

Means in a column with the same letter are not significantly different. calculations of nematode egg production show that the reduced fecundity on resistant genotypes is likely to have a major effect on the numbers of clover cyst nematodes in pasture where these resistant plants are used. 
Our finding that resistance to clover cyst nematode can be improved by further selection raises issues for the long-term use of resistant cultivars (Young 1992): 1) nematode species unaffected by the resistance may increase in incidence, 2) resistance-breaking races of clover cyst nematodes may be selected for, and 3) the resistant seedlines may be more sensitive to parasitism than their parent material (Roberts 1992). The last named was not indicated in our work as all resistant seedlines grew well, but we plan to monitor yield in glasshouse and field trials. The other two issues would require field study over several seasons.

\section{Conclusion}

The differences in numbers of cysts between resistant and susceptible lines increased during two generations of selection, supporting earlier results that indicated that progress in breeding for resistance was possible. Furthermore, the resistance is acting on clover cyst nematode egg production which would further reduce recruitment to later generations of the clover cyst nematode. We believe that this breeding programme will result in a white clover cultivar with useful levels of resistance to a widespread pest.

\section{ACKNOWLEDGEMENTS}

Thanks to John Grant and Ian Black for technical assistance.

\section{REFERENCES}

Dijkstra, J. 1971. Breeding for resistance to Heterodera in white clover. Euphytica 20: 36-46.

Kuiper, K. 1960. Resistance of white clover varieties to the clover cyst-eelworm, Heterodera trifolii Goffart. Nematologica (Suppl. II, 1960): 95-96.

Mercer, C.F.; Cooper, B.M.; Grant, J.L. 1992. Selection for resistance and tolerance of 18 lines of white clover to root knot (Meloidogyne hapla) and clover cyst (Heterodera trifolii) nematodes. New Zealand journal of agricultural research 35: 219-224.

Mercer, C.F.; Grant, J.L. 1993. Reproduction of Meloidogyne hapla and Heterodera trifolii from several sites in New Zealand on resistant and susceptible lines of white clover. Nematologica 39: 312-321.

Mercer, C.F.; Woodfield, D.R. 1986. A survey of root knot and clover cyst nematodes in dry hill country. New Zealand journal of agricultural research 29: 129-135.
Norton, D.C. 1967. Relationships of Heterodera trifolii to some forage legumes. Phytopathology 57: 13051308.

Roberts, P.A. 1992. Current status of the availability, development, and use of host plant resistance to nematodes. Journal of nematology 24: 213-227.

Skipp, R.A.; Gaynor, D.L. 1987. Pests - Nematodes. pp. 493-512. In: Baker, M.J.; Williams, W.M. (ed.). White clover. CAB International.

van den Bosch, J.; Mercer, C.F. 1996a. Variation in white clover for root-knot nematode resistance. New Zealand journal of agricultural research 39: 137148.

van den Bosch, J.; Mercer, C.F. 1996b. Third generation progress in breeding white clover for resistance to the root-knot nematode. White Clover: New Zealand's Competitive Edge. Agronomy Society of New Zealand/ New Zealand Grassland Association Joint Symposium: 163-166.

van den Bosch, J.; Mercer, C.F.; Grant, J.L. 1993b. Progress in breeding white clover for resistance to the root-knot nematode. Proceedings of the 10th Australian Plant Breeding Congress Vol 2: 121122.

van den Bosch, J.; Mercer, C.F.; Grant, J.L 1997. Variation in white clover for resistance to clover cyst nematode. New Zealand journal of agricultural research (in press).

van den Bosch, J.; Mercer, C.F.; Grant, J.L.; Black, I.K. 1993a. Clover cyst nematode resistance in white clover. Proceedings of the 17th International Grassland Congress: 928-929.

Watson, R.N.; Bell, N.L.; Neville, F.J.; Harris, S.L. 1994. Improving pasture sustainability by reducing the impact of clover nematodes. pp. 83-85. In: Pankhurst, C.E. (ed.). Soil Biota: Management in Sustainable Farming Systems. Australia: CSIRO.

Watson, R.N.; Yeates, G.W.; Littler, R.A.; Steele, K.W. 1985. Responses in nitrogen fixation and herbage production following pesticide applications on temperate pastures. pp. 103-113. In: Chapman, R.B. (ed.). Proceedings of the 4th Australasian Conference on Grassland Invertebrate Ecology. Lincoln College, Canterbury, 13-17 May 1985. Caxton Press.

Widdowson, J.P.; Yeates, G.W.; Healy, W.B. 1973. The effect of root nematodes on the utilisation of phosphorus by white clover on a yellow-brown loam. New Zealand journal of agricultural research 16 : 77-80.

Wood, F.H.; Foot, M.A. 1977. Decontamination of potato tubers grown in soil infested with potato cyst nematodes. New Zealand journal of experimental agriculture 5: 315-319. 
Yeates, G.W. 1977. Soil nematodes in New Zealand pastures. Soil science 123: 415-421.

Yeates, G.W.; Healy, W.B.; Widdowson, J.P. 1973. Screening of legume varieties for resistance to the root nematodes Heterodera trifolii and Meloidogyne hapla. New Zealand journal of agricultural research 16: 81-86.

Young, L.D. 1992. Problems and strategies associated with long term use of nematode resistant cultivars. Journal of nematology 24: 228-233. 
